\title{
Os produtores cinematográficos e o Estado na Argentina e no Brasil (1930-1945)
}

\author{
Arthur Autran Franco de Sá Neto' \\ I - UFSCAR \\ São Carlos (SP), Brasil
}

Resumo: Este artigo descreve e analisa as relações entre Estado e produtores cinematográficos na Argentina e no Brasil no período de 1930 a 1945, buscando também comparar ambas. No Brasil, o Estado adotou postura protecionista em relação ao cinema bem antes da Argentina, entretanto, isso não foi suficiente para fazer a produção de longas-metragens avançar no mercado. Na Argentina, o protecionismo foi mais tardio, porém ele tomou maior proporção do que no Brasil. Afigura-se também que, em ambos os casos, o protecionismo foi uma forma entre outras de o Estado tentar controlar ideologicamente a produção.

Palavras-Chave: Estado; produção cinematográfica; Argentina; Brasil; história do cinema.

Abstract: Producers and the State in Argentina and Brazil (1930-1945) - This article describes and analyzes the relations between the State and film producers in Argentina and Brazil from 1930 to 1945, also seeking to compare them both. In Brazil, the state adopted a protectionist stance in relation to cinema well before Argentina; however, this was not enough to make the production of feature films advance in the market. In Argentina, protectionism had a late start, but it acquired a greater dimension than in Brazil. It also appears that, in both cases, protectionism was a way, among others, of the state trying to control production ideologically.

Key Words: State; Film Production; Argentina; Brazil; Film History.

\section{Introdução}

Este artigo é parte integrante de uma pesquisa que busca explicar as diferenças no desenvolvimento das cinematografias da Argentina e do Brasil nos anos 1930 e 1940 analisando diversas questões de forma comparativa. 
No que diz respeito ao presente artigo, objetiva-se compreender as relações entre os produtores e o Estado nos dois países. Elas serão abordadas por meio da investigação em torno das associações de classe dos produtores e da sua ação de representação junto ao Estado, das políticas do Estado direcionadas para o campo cinematográfico e das influências e das pressões do Estado sobre os produtores.

No que tange à história do cinema, o interregno 1930-1945 corresponde, grosso modo, à introdução do som na produção de ambos os países, bem como à adaptação desses mercados à novidade. No período, surgiram importantes produtoras inspiradas na concepção do Studio system, tais como Cinédia, Brasil Vita Filmes, Sonofilmes, Atlântida, Argentina Sono Films, Lumiton, Río de la Plata e Estudios San Miguel. Também astros e estrelas ganharam grande notoriedade, como foi o caso de Carmen Miranda, Oscarito, Libertad Lamarque e Luis Sandrini.

Conforme veremos, no Brasil, a partir de 1932, já havia legislação protecionista de maneira a obrigar que um curta-metragem nacional fosse exibido antes de cada longa estrangeiro; na Argentina, a ação do Estado no período tendeu a ser mais tímida, só em 1943 foi instituída a primeira legislação a prever algum tipo de cota de tela, também relativa à exibição compulsória de um complemento nacional (documentário ou cinejornal) antes do longa.

No que pese essa diferença, a produção do país vizinho floresceu em termos industriais, chegando a anotar 56 longas-metragens lançados comercialmente em 1942 (GETINO, 1998, p. 337), passando a ter forte presença no mercado interno e a ser o principal exportador latino-americano de filmes ${ }^{1}$; já no Brasil, a atividade tendeu a se concentrar nos curtas, com a produção de longas-metragens ficando bastante restrita em 1942, por exemplo, foram produzidos apenas oito longas (JOHNSON, 1987, p. 201).

É significativo notar que enquanto Domingo di Núbila entende o período de 1933 a 1942 como a "época de ouro" do cinema argentino, dando mesmo título ao primeiro volume da reedição da sua Historia del cine argentino (1998), já Alex Viany, na Introdução ao cinema brasileiro, qualifica de "fase amarga" as décadas de 1930 e 1940 (1959, p. 124).

Minha hipótese inicial de trabalho é que a política cinematográfica brasileira da primeira passagem de Getúlio Vargas pelo poder não foi apenas insuficiente - como já destacaram diversos autores a exemplo de Jean-Claude Bernardet (2009, p. 53) -, mas foi mesmo deletéria por não permitir o desenvolvimento industrial.

No que tange à política, a década de 1930 caracterizou-se pela instabilidade tanto na Argentina quanto no Brasil. Em ambos os países, o ano de 1930 foi marcado por grandes mudanças: no Brasil, com a chegada de Vargas ao poder através da derrubada

1 No período analisado nesse artigo, 1930-1945, Argentina e México disputaram o posto de principal produtor cinematográfico latino-americano e também de polo de exportação mais importante, com o primeiro país destacando-se até 1942. A partir do ano seguinte, a crise na produção argentina, em decorrência da falta de filme virgem e do forte apoio do Estado mexicano ao cinema do seu país, levaram a situação a se inverter. (GETINO, 1998, p. 36-38). 
do presidente Washington Luís; na Argentina, com a ascensão dos militares por meio do golpe comandado pelo general José Félix Uriburu. Ao longo da década, Vargas consolidou-se no poder instaurando em 1937 a ditadura do Estado Novo no que pese a sublevação capitaneada pela oligarquia paulista em 1932, o levante comunista de 1935 e a tentativa de golpe integralista em 1938. Na Argentina seguem-se na presidência o general Agustín P. Justo (1932-1938) e Roberto M. Ortiz (1938-1942), ambos eleitos em pleitos marcados por fraudes. Ortiz adoeceu e foi substituído pelo vice, Ramón Castillo, o qual foi derrubado em 1943 por novo golpe militar. Com isso, ascendeu ao poder o general Pedro Ramírez, que deu lugar em 1944 ao general Edelmiro Farrell. Em 1945, terminou a ditadura do Estado Novo e o Brasil assistiu às eleições nas quais o general Eurico Gaspar Dutra foi sufragado presidente. Enquanto isso, desde 1944 cristalizava-se a força política de Juan Domingo Perón na Argentina, então secretário do Trabalho e Previdência, e que em 1946 chegou à presidência da República pela via eleitoral.

Uma diferença central entre os dois países diz respeito à força do nacionalismo no campo político. Segundo Boris Fausto e Fernando J. Devoto:

Pelo menos as figuras mais notórias dos nacionalismos argentinos não tiveram influência no delineamento de políticas de Estado, ao contrário de seus congêneres brasileiros, em especial no terreno institucional, trabalhista e educacional. Basta pensar no papel desempenhado por figuras, mais autoritárias do que totalitárias, como Oliveira Vianna, Francisco Campos ou Azevedo Amaral, antes e durante o Estado Novo. Na Argentina, a maioria dos nacionalistas fora mantida longe do poder (mesmo durante o breve governo de Uriburu), e sua influência intelectual sobre as políticas governamentais foi escassa na década de 1930. (FAUSTO; DEVOTO, 2004, p. 248)

Esta diferença certamente teve reverberação no campo cinematográfico, pois a legislação protecionista tornou-se possível no Brasil pelo entendimento do cinema como veículo de educação e cultura por parte de intelectuais nacionalistas comprometidos com reformas no campo educacional, tais como Edgard Roquette-Pinto.

\section{Estado e produtores no Brasil}

O estruturação nos anos 1930 de estúdios comandados por produtores como Adhemar Gonzaga - Cinédia - e Carmen Santos - Brasil Vita Film - no Brasil ou D. Angel Mentasti - Argentina Sono Film - e Enrique Susini - Lumiton - na Argentina representou notável ampliação em termos dos capitais investidos na produção quando comparados com o período do cinema silencioso.

No caso brasileiro, a dificuldade de acesso do produto nacional ao mercado ocupado pelo filme norte-americano certamente era uma questão que preocupava os produtores, levando-os a apelar para alguma forma de intervenção do Estado. Documento relevante 
é a carta escrita em 1931 pelo produtor de Piloto 13 (Achille Tartari, 1929), Arlindo Augusto do Amaral, a Getúlio Vargas. O missivista entende que:

O que vem impedindo o desenvolvimento do cinema nacional não é por certo o imposto sobre a película virgem, mas tão somente a constante recusa por parte dos exibidores de passarem os filmes nacionais, ora alegando defeitos, ora por não terem as grandes montagens ${ }^{2}$ dos filmes americanos, ora aceitando-os para em seguida sacrifica-los com uma péssima distribuição, ou finalmente exigindo do produtor nacional gastos enormes, para logo após faltarem aos compromissos assumidos [...] (AMARAL, 1931)

Após explicar como a Paramount teria prejudicado a comercialização de Piloto 13. Arlindo Augusto do Amaral apresenta longamente uma série de números sobre os custos e as rendas de filmes norte-americanos no Brasil, além de considerações de ordem moral a respeito do seu conteúdo. Tudo isso para chegar ao cerne da questão: "Para que a cinematografia nacional se desenvolva é necessário que uma lei federal exija na programação diária em cada cinema, um jornal nacional e um filme de arte também nacional" (AMARAL, 1931). Ou seja, era necessário que o Estado interviesse no sentido de garantir um espaço mínimo para o produto nacional no mercado.

Também ficou claro para os produtores que era preciso algum tipo de articulação entre eles visando defender seus interesses comuns. Em janeiro de 1932 foi criada por sugestão de Eurico de Oliveira a ACPB (Associação Cinematográfica de Produtores Brasileiros) (ATA, 1932). Integravam o quadro da associação no momento da sua organização Adhemar Gonzaga, Carmen Santos, Eurico de Oliveira, Armando de Moura Carijó - o presidente da associação -, Paulo Benedetti, Fausto Muniz, Jayme Pinheiro, Alberto Botelho e João Stamato, entre outros (PELA, 1932, p. 3). Pouco depois da criação da ACPB, um grupo de produtores visitou Getúlio Vargas e entregou a ele o título de presidente de honra da associação, ademais de solicitar a aprovação do projeto elaborado por comissão designada pelo ministro da Educação (PROPUGNANDO, 1932). Essa homenagem a Vargas foi apenas uma das primeiras, pois ao longo da década de 1930 ele se tornou uma espécie de "grande pai" do cinema brasileiro. Entre outras honrarias, ele teve sua foto com a legenda "Benemérito n. I do Cinema Brasileiro" publicada no relatório da ACPB datado de 1937, com o retrato de dona Darcy Vargas - sua esposa - compondo o final do longa-metragem de ficção Aves sem ninho (Raul Roulien, 1939) e uma foto do ditador estampada na capa do número um da revista corporativa Cinema Brasileiro, publicada em 1940, com os dizeres "O maior amigo do Cinema Brasileiro". Tratava-se de uma relação entre cineastas e Estado marcada claramente pelo paternalismo (AUTRAN, 2013, p. 140-141).

O comércio cinematográfico, ou seja, os distribuidores e exibidores, já se encontrava no início dos anos 1930 mais organizado quando comparado com o filão da produção. Em 1931, importadores de filmes e exibidores congregaram-se na Associação Brasileira

2 Montagem na acepção utilizada pelo produtor de Piloto 13 significa cenário. 
Cinematográfica, que foi responsável pela Convenção Brasileira Cinematográfica, ocorrida em janeiro de 1932. Nesta ocasião, o representante da associação, Ademar Leite Ribeiro, reivindicou a diminuição dos impostos alfandegários que incidiam sobre a importação de película cinematográfica, pois, conforme registra Anita Simis, a baixa do câmbio havia elevado os preços do filme importado, tanto impresso quanto virgem. A mesma autora indica que esse também foi um fator importante para a organização dos produtores na já mencionada ACPB, pois estes defendiam a diminuição de impostos para a película virgem (SIMIS, 1996, p. 99-100).

É de se notar que na ata da reunião na qual foi decidida a criação da ACPB fica patente a tensão em relação aos distribuidores de filmes estrangeiros e exibidores pelo "voto de veemente protesto" contra o título da convenção então recentemente ocorrida, demonstrando uma postura nacionalista pela qual verdadeiramente brasileiros ou nacionais seriam os produtores de filmes realizados no Brasil. Também merece ser citado o trecho final da ata, que reproduz o texto de telegrama a ser enviado ao ministro da Educação:

\begin{abstract}
A Associação Cinematográfica dos Produtores Brasileiros aguarda publicação projeto lei-projeto cinematográfica [sic] a fim de apresentar a V. Excia. memorial de suas necessidades visando engrandecimento da indústria nacional e satisfazendo os altos fins educativos que o governo tem em vista com a sua promulgação. (ATA, 1932)
\end{abstract}

O telegrama demonstra que os produtores já tinham no seu horizonte a importância da questão educacional para o governo, mas, ao mesmo tempo, fica indicado que se pretendia o apoio do Estado ao cinema de caráter industrial, entendido então como o filme narrativo de ficção feito com base no estúdio.

O projeto a que os produtores se referiam foi elaborado por uma comissão presidida pelo então ministro da Educação, Francisco Campos, e integrada por M. A. Teixeira de Freitas, Jônatas Serrano, Francisco Venâncio Filho, Mario Behring, Adhemar Gonzaga e Ademar Leite Ribeiro, entre outros nomes (SOUZA, 2003, p. 70). A composição da comissão era bastante diversa, envolvendo desde, obviamente, a representação do governo, mas passando por gente ligada à educação, à imprensa, à produção e à exibição cinematográficas. Ou seja, o Governo Provisório de Vargas buscou articular na comissão os vários setores que naquele momento tinham interesses em relação ao cinema e reclamavam algum tipo de ação do Estado.

No caso dos educadores, a atuação da ABE (Associação Brasileira de Educação) foi bastante intensa. Segundo José Inácio de Melo Souza, o organismo "parece ter sido o grupo civil que mais se interessou pelo cinema e pelo rádio, misturando doses de espírito repressivo, sobre o que era considerado por essa elite como nocivo ao público, com esforços dirigidos para a educação de massa". Nesse sentido, a ABE e educadores como Edgard Roquette-Pinto ou Anísio Teixeira defendiam a atenção do Estado para com 
o cinema educativo e a adoção de "uma censura cultural, uniforme e federalizada" (2003, p. 69-70), pois até então a censura era exercida de forma descentralizada e sem regras válidas para todo o país.

A 04 de abril, Francisco Campos e Oswaldo Aranha assinavam o decreto 21.240/1932, que, dentre várias medidas, centralizou a censura na instância federal, criou o DPDC (Departamento de Propaganda e Difusão Cultural), diminuiu a tarifa aduaneira para o filme virgem e o impresso e criou a obrigatoriedade de exibição do filme brasileiro no caso, embora a lei previsse a possibilidade de exibição de longas-metragens, especificava somente em relação ao curta a obrigatoriedade de um filme educativo acompanhando o longa-metragem estrangeiro em cada sessão. Esta lei é extremamente importante para a história das relações entre Estado e cinema no Brasil. Como assinala Anita Simis:

Trata-se de uma medida de caráter sistêmico que constituiu a base de um padrão ideológico e político da relação Estado/sociedade. Seus artigos sintetizam conveniências de vários setores, tratando desde o cinema educativo até o cinema comercial, da censura até a estruturação de órgãos estatais. No entanto, a análise do decreto em si não deve concluir que a medida pretendia apenas atender aos interesses envolvidos, como se fosse uma somatória de artigos que contemplaram pressões e conflitos. O sentido interventor do decreto era trazer os conflitos expressos para uma solução disciplinadora, sem mediações e centralizadora. (SIMIS, 1996, p. 93)

Destarte, é possível indicar que, em relação ao produto cinematográfico brasileiro, o decreto 21.240 abriu algum espaço para ele de forma a incorporá-lo ao projeto ideológico do governo, ou seja, como um instrumento - na forma do curta-metragem educativo - para a difusão e imposição de determinados padrões culturais entendidos como verdadeiramente brasileiros e que, portanto, deveriam integrar todo o povo da nação.

Ao mesmo tempo, o decreto buscava não alterar as relações de força no mercado cinematográfico, reconhecendo implicitamente a dominação do filme estrangeiro e criando um espaço para o produto nacional - ainda que tal espaço fosse diminuto.

A partir de então, boa parte dos esforços políticos dos produtores concentrou-se na implementação da lei de exibição obrigatória do curta-metragem - a qual ocorreria apenas em 1934 - e na sua fiscalização. Eles tinham esperanças que por meio da proteção ao curta-metragem se conseguisse condições para viabilizar a produção de longas, vide o texto do Projeto de Lei de Proteção à Indústria do Filme Brasileiro, elaborado pela ACPB em 1933 e enviado a Getúlio Vargas. Este projeto previa tão somente a obrigatoriedade de exibição do curta.

Tal dispositivo é o maior anhelo dos produtores nacionais e aquele que maior animação virá dar aos estúdios brasileiros, proporcionando-lhes desde logo, ambiente para realizações mais arrojadas. Os produtores podem afirmar que dele depende a existência de um cinema brasileiro. (Apud CARIJÓ, 1937, p. 30) 
Afigura-se que as "realizações mais arrojadas" seriam os longas de ficção, porém, ao contrário do que desejavam os produtores, isso não ocorreu. A produção cinematográfica ampliou-se a partir de 1934, mas exclusivamente em função do filme curto³. Em 1939, a legislação protecionista foi timidamente estendida para o longa-metragem por meio do decreto-lei 1.949: cada sala deveria exibir compulsoriamente um filme brasileiro por ano.

Anita Simis dá conta ainda da constituição da DFB (Distribuidora de Filmes Brasileiros), instituída como organização comercial em 1935 e que contava entre seus acionistas com a própria ACPB, além de Adhemar Gonzaga, Alberto Botelho, Armando de Moura Carijó e Jayme Pinheiro, entre outros. A DFB centralizou a distribuição dos curtas-metragens brasileiros possuindo como finalidades "evitar que a fiscalização ficasse prejudicada e para que não houvesse concorrência entre as distribuidoras, rebaixando os preços" (SIMIS, 1996, p. 112). A DFB também comercializava longas-metragens e foi a primeira tentativa na história do cinema brasileiro de uma empresa que concentrasse a distribuição do filme nacional.

Em 1936 foi criado o INCE (Instituto Nacional do Cinema Educativo), órgão ligado ao então Ministério da Educação e Saúde. O INCE, como o próprio nome já indica, era voltado para a produção de filmes educativos e/ou de viés cultural, predominando na sua filmografia o curta-metragem de não-ficção. Seu primeiro diretor foi Edgard Roquette-Pinto, tendo como principal nome ligado ao cinema nada mais nada menos do que Humberto Mauro. O caráter imprimido ao INCE por Roquette-Pinto é mais um sinal claro de que o Estado brasileiro entendia o cinema nacional como veículo eminentemente de educação e cultura. Outro viés importante para o Estado era a propaganda ideológica e, nesse sentido, foi fundamental a instituição do DIP (Departamento de Imprensa e Propaganda) em 1939, órgão dirigido por Lourival Fontes que, entre várias ações ligadas à divulgação do Estado Novo, produziu o Cine Jornal Brasileiro, além de documentários de curta-metragem.

\section{Estado e produtores na Argentina}

César Maranghello anota que já no final da década de 1920 o periódico La Película defendeu a adoção de medidas protecionistas para a produção argentina e citava como exemplos os casos da Inglaterra, da Itália, da Alemanha e da França. Ademais, em 1932, o conselheiro municipal socialista González Porcel apresentou em Buenos Aires projeto de lei visando estimular a produção local (MARANGHELLO, 2000, p. 24).

Apesar destes movimentos, a legislação protecionista argentina foi mais tardia do que a brasileira, o que não significa a inexistência de propostas ao longo dos anos envolvendo Estado e cinema. Em 1933 surgiu o primeiro ordenamento federal visando regular a atividade cinematográfica, bem como foi criado o Instituto Cinematográfico Argentino.

3 A produção de longas-metragens no Brasil entre 1930 e 1945 é seguinte: $1930=18 / 1931=17 / 1932=14$ $/ 1933=10 / 1934=7 / 1935=6 / 1936=7 / 1937=6 / 1938=8 / 1939=7 / 1940=13 / 1941=4 / 1942$ $=8 / 1943=8 / 1944=9 / 1945=8(J O H N S O N, 1987$, p. 201) . 
Entretanto, por falta de recursos o instituto começou a operar somente em 1936. O senador Matías Sánchez Sorondo foi catapultado à presidência do órgão e o crítico Carlos Alberto Pessano à sua direção técnica. Ambos eram conservadores e pretendiam gerir o órgão com base em ideias nacionalistas e católicas (KRIGER, 2009, p. 27-28).

Ao longo de 1937, Sanchéz Sorondo viajou para a Itália e a Alemanha a fim de entender como o Estado se relacionava com o cinema nestes países, dada a sua admiração pelos regimes totalitários ali implantados, bem como foi à França e à Inglaterra para conhecer os estúdios locais (CAMPODÓNICO, 2005, p. 64-65 e 68).

No ano seguinte, o senador propôs junto ao Congresso Nacional um projeto de lei para o cinema, entretanto, ele foi rejeitado. Diversos setores não aceitaram o projeto, tanto porque ele previa a concentração de decisões nas mãos das autoridades do Instituto Cinematográfico Argentino alijando dessa forma as associações representativas do meio cinematográfico, como também pelas fortes medidas protecionistas propostas (KRIGER, 2009, p. 29).

Segundo Maranghello, o senador Matías Sanchéz Sorondo tinha por fim "converter o cinema em um elemento de pedagogia política, um meio governamental de propaganda totalitária". Mas, dada a rejeição ao projeto de lei, as funções do Instituto Cinematográfico Argentino ficaram limitadas à realização de filmes de propaganda do governo e/ou do país, de informação ou educacionais; bem como o órgão poderia proibir a exportação de obras tidas como deletérias à imagem nacional (MARANGHELLO, 2000, p. 39 e 45).

Para Clara Kriger:

Até 1939 as negociações das empresas produtoras, de diferentes envergaduras, com as companhias distribuidoras de filmes e com os donos de salas de cinema não pareciam necessitar de mediadores. [...]

O começo da Segunda Guerra Mundial marcou uma mudança definitiva no mercado cinematográfico em decorrência da escassez de matéria prima, já que a nitrocelulose que se utilizava para fabricar filme virgem era também um material indispensável para a fabricação de explosivos. A falta de insumos afetou as cinematografias de todos os países, mas foi particularmente grave na Argentina, porque seu principal fornecedor, os Estados Unidos, implementou um boicote econômico em relação ao mercado local em resposta à posição neutra que o país manteve no conflito bélico. A medida provocava também um efeito secundário: aplacar o crescimento industrial do setor que, ainda que não fosse um polo de concorrência real para o cinema hollywoodiano, havia conseguido conquistar uma parte do mercado local e do latinoamericano. (KRIGER, 2009, p. 29-30)

Somente em dezembro de 1943 entrou em vigor a primeira legislação protecionista voltada para o cinema argentino. A APPA (Asociación de Productores de Películas Argentinas) havia entregue um memorial ao governo e pouco depois foi determinada a exibição obrigatória de um cinejornal ou de um documentário de curta-metragem em cada sessão nas salas de cinema. Os únicos beneficiados pela medida foram o produtor 
Antonio Angel Díaz e a Argentina Sono Film, pois, o primeiro produzia o cinejornal Sucesos Argentinos e a segunda o Noticiario Panamericano. No mesmo ano, o Instituto Cinematográfico Argentino foi absorvido pela Subsecretaria de Imprensa e Difusão (MARANGHELLO, 2000, p. 30 e 48).

O adensamento do intervencionismo estatal no campo cinematográfico não foi casual. O movimento militar que assumiu o poder em 1943 já apontava para a reorganização do Estado no sentido de ampliar a sua presença nos mais diferentes setores, característica depois reforçada com o peronismo (KRIGER, 2009, p. 33).

O principal contencioso entre produtores e exibidores girava em torno da forma de pagamento dos filmes. Com a crise na produção, advinda da falta de película virgem, os produtores entendiam que os exibidores deveriam pagar o aluguel dos filmes a partir de uma porcentagem do que fora obtido nas bilheterias e não mais a preço fixo, como até então ocorria. Os exibidores negaram-se a fazer esta alteração, pois economicamente Ihes interessava manter o esquema de preço fixo e, por fim, tal situação resultou em conflito entre os dois setores (MARANGHELLO, 2000, p. 58). Sintoma das mudanças que começavam a acorrer no Estado argentino, em 1944 foi decretada a lei 21.344, a qual teve a arbitragem de Juan Domingo Perón na sua negociação - então ainda secretário do Trabalho e da Previdência. Esta lei previa que os pagamentos dos exibidores aos produtores deveriam ser realizados pelo sistema de percentagem, bem como determinava a obrigatoriedade dos cinemas de primeira linha da Capital Federal, com mais de 2.500 lugares, exibirem no mínimo um longa-metragem argentino ao longo de sete dias a cada dois meses, enquanto que nas outras salas de primeira linha da Capital Federal seria exibido um filme nacional durante sete dias a cada mês e, finalmente, o restante das salas do país deveria apresentar o produto argentino em pelo menos duas de cada cinco semanas (KRIGER, 2009, p. 37). Maranghello considera que a lei 21.344 iniciou a "dependência do apoio estatal", que se aprofundou ao longo de toda a primeira passagem de Perón pela presidência da República (MARANGHELLO, 2005, p. 112).

\section{Considerações Finais}

É de se observar as diferenças quando comparamos a política cinematográfica dos dois países. No Brasil, o Estado teve o condão de aglutinar em torno de si, já no início dos anos 1930, os diversos setores implicados na questão cinematográfica e impor a eles a perspectiva governamental, a qual, no caso da produção, tinha um viés culturalista ou seja, preocupado unicamente com o cinema como veículo de elementos culturais considerados nacionais - e deixou inteiramente de lado qualquer objetivo industrialista. Já na Argentina, o Estado não conseguiu em um primeiro momento arregimentar os setores ligados à produção, à distribuição e à exibição, nem ter forças para impor os seus ditames.

Algumas explicações para esta diferença podem ser encontradas no fato de que na década de 1930 no Brasil já imperava uma "ideologia mais estatista" - que levou 
o Estado brasileiro no período de 1930-1945 a aumentar bastante sua participação no PIB -; bem como porque no Brasil o poder tendeu a se concentrar neste período, enquanto na Argentina a propensão foi de fragmentação entre vários grupos em disputa, inclusive no interior do aparelho do Estado (FAUSTO; DEVOTO, 2004, p. 262 e 271).

A ideologia menos estatista imperante então na Argentina e a fragmentação do poder acarretavam o enfraquecimento já de saída das propostas que visavam enquadrar a produção cinematográfica. Ao contrário do caso brasileiro, em que o decreto 21.240 expressava a hegemonia a partir do Estado a qual se projetava para o campo cinematográfico, o projeto de lei elaborado pelo senador Sanchéz Sorondo representava as ideias dos setores mais conservadores da política argentina sem ter conseguido obter predominância ideológica e política. Entretanto, é de se notar que o projeto de Sanchéz Sorondo deixou marcas e inspirou parcialmente formas de intervenção posteriormente adotadas pelo Estado argentino (CAMPODÓNICO, 2005, p. 74). É necessário levar em conta que o cinema educativo assumiu papel relevante para o Estado brasileiro devido às altas taxas de analfabetismo do país. Sem embargo dos esforços em torno da educação formal para combater o problema, o cinema educativo era percebido como uma espécie de livro para aqueles que não tinham instrução básica. Na Argentina, o problema não se colocava da mesma forma, inclusive porque as taxas de analfabetismo eram bem mais baixas ${ }^{4}$.

Ademais, no Brasil ,desde os anos 1920, existiam demandas do meio cinematográfico em torno de formas de protecionismo para a produção nacional, bastando mencionar como exemplo a campanha de Adhemar Gonzaga e Pedro Lima nas páginas de Cinearte em defesa da isenção de impostos para o filme virgem e da obrigatoriedade de exibição. Isso facilitava a atração do meio cinematográfico para os braços do Estado ${ }^{5}$. Na Argentina, a luta pelo protecionismo não foi marcante neste período e nem na década posterior.

Entretanto, com a Segunda Guerra Mundial e a decorrente escassez de filme virgem, os produtores argentinos ficaram fragilizados e tiveram de se voltar para o Estado. Além disso, em 1943 ocorreu um levante militar e os novos donos do poder defendiam o aprofundamento da intervenção do Estado na sociedade, o que incluía a consciência mais generalizada e aprofundada a respeito da importância dos meios de comunicação de massa. Isso resultou no adensamento das relações entre cinema e Estado, levando à tomada de medidas protecionistas. Embora algumas delas tivessem um viés que também se pode chamar de culturalista, por outro lado houve medidas claramente industrialistas, como a obrigação de os exibidores pagarem o aluguel dos filmes aos produtores pelo sistema de percentagem.

Afigura-se que minha hipótese inicial de trabalho de a política cinematográfica brasileira do período ter sido deletéria ao não permitir o crescimento industrial pode

4 Para efeito de comparação observar que em 1930 o analfabetismo no Brasil atingia por volta de $60 \%$ da população com mais de quinze anos, enquanto na Argentina ele estava na faixa de 25\% (FAUSTO;DEVOTO, 2004, p. 153).

5 Sobre a campanha de Adhemar Gonzaga e Pedro Lima ver Humberto Mauro, Cataguases, Cinearte, de Paulo Emílio Salles Gomes (1974). 
ser reestruturada de uma forma mais refinada. Seria de sugerir que, para além de deletéria industrialmente, a postura do governo de Getúlio Vargas buscou de maneira profilática controlar a produção de imagens cinematográficas que possibilitassem a construção de uma representação do Brasil reveladora da presença do negro, do morro, do samba, da pobreza, etc.

É de se notar que alguns dos primeiros sucessos de público do cinema brasileiro no período sonoro, com destaque para Favela dos meus amores (Humberto Mauro, 1935), apresentavam por vezes essas imagens e eram um elogio à música popular, em um processo no qual a indústria cultural começava a germinar e a buscar o seu espaço no contexto de uma sociedade bastante fechada.

Na Argentina, as imagens da pobreza, dos imigrantes, do tango, dos conflitos sociais e da prostituição, mesmo que de maneira romantizada, estão bem mais fixadas no cinema do período, bastando pensar em fitas como Tango! (Luis José Moglia Barth, 1933), Riachuelo (Luis José Moglia Barth, 1934), Mujeres que trabajan (Manuel Romero, 1938) e La canción de los barrios (Luis César Amadori, 1941). Nas películas argentinas, o tango é apresentado como a música com origem na base da sociedade, mas que se tornaria representativa de toda a nação, ou, como aponta Mario Berardi, o tango é uma "metáfora" da identidade nacional (BERARDI, 2006, p. 37).

E Martin Karush entende que até a ascensão de Perón:

A profunda marca classista do melodrama da cultura de massas argentina implicou que o cinema e o rádio continuassem identificando a nação com os pobres e atacando os ricos como egoístas, hipócritas e antinacionais. (KARUSH, 2013, p. 223)

Afigura-se que a relativa fragilidade do Instituto Cinematográfico Argentino e a inexistência de medidas protecionistas até 1943 retiravam do Estado parte do poder de influenciar e pressionar os produtores, uma situação diferente do Brasil. Na avaliação de Clara Kriger, ao comentar os primeiros anos das relações entre Estado e cinema na Argentina, até 1943 havia "pouca capacidade transformadora da política estatal para este setor industrial" (KRIGER, 2009, p. 32).

A maioria dos filmes ficcionais brasileiros do período passava longe do tipo de representação mencionado por Karush. A política cinematográfica do governo Getúlio Vargas teve o condão não apenas de produzir curtas-metragens que expressavam o que o Estado entendia por cultura nacional, mas ela ainda dificultava a produção de imagens em movimento apresentando o país de forma diferente do que os intelectuais a serviço do Estado entendiam como a verdadeira representação do Brasil. Isso por meio inclusive de uma enorme cobrança em relação aos produtores das benesses concedidas pelo governo na forma da tímida legislação protecionista. Vide, por exemplo, o trecho seguinte de um discurso de Edgard Roquette-Pinto datado de 1936:

Lembrem-se, porém, os cinematografistas brasileiros que os grandes favores obtidos foram pelo Chefe do Governo Provisório, sujeitos a uma cláusula solene: 
"O Cinema deve, cada vez mais, auxiliar a educação do povo."

Isto já não é um dever; é mesmo uma glória. (Apud CARIJÓ, 1937, p. 201)

Esta política cinematográfica foi eficiente a ponto de influenciar ideologicamente longas financiados por produtores privados. Por exemplo, O grito da mocidade (1936), fita cuja produção gerou muitas expectativas pois era dirigida e estrelada por Raul Roulien o brasileiro que teria triunfado em Hollywood -, mas, uma vez lançada, foi criticada pela revista A Scena Muda, entre outras razões, pelo insistente tom de apelo ao patriotismo (MARIÑO, 2016, p. 205). A Cinédia prestou seu tributo ao Estado Novo por meio de Romance proibido (1939-1944), película dirigida pelo próprio dono da produtora, Adhemar Gonzaga, e que apresenta a personagem central, a professora Gracia, levando a um rincão do país uma mentalidade educacional em tudo coincidente com a defendida pelo governo. Como afirma o pesquisador Maurício Reinaldo Gonçalves, Romance proibido "é um exemplo significativo de como o discurso estadonovista impregna-se no discurso cinematográfico de ficção e o transforma em veículo do ideário do regime" (2009, p. 6). E não se pode deixar de citar Argila (1940), fita dirigida por Humberto Mauro, produzida e estrelada por Carmen Santos, caracterizada pelo historiador Claudio Aguiar Almeida como "uma cena do Estado Novo" (1999). Finalmente, o interminável Inconfidência Mineira (1938-1948) foi lançado depois da queda de Vagas, mas a gênese do filme, realizado e estrelado por Carmen Santos, está ligada ao Estado Novo - o INCE chegou a contribuir com a produção por meio da "correção" do roteiro, solicitando a mesma ao historiador Afonso de E. Taunay. É de observar que todos estes filmes foram rotundos fracassos de público.

Em grande medida dominados pelo Estado, tanto em termos políticos quanto ideológicos, os produtores no Brasil tinham pouco espaço para fazer filmes que de alguma forma escapassem à perspectiva do governo de Vargas.

Arthur Autran Franco de Sá Neto é professor do Depto. de Artes e Comunicação da Universidade Federal de São Carlos. É doutor pelo Instituto de Artes da Unicamp. Dirigiu o curta-metragem Minoria absoluta (1995) e o longa-metragem A política do cinema (2011), ambos documentários. Publicou os livros Alex Viany: crítico e historiador (2003), Imagens do negro na cultura brasileira (2011) e O pensamento industrial cinematográfico brasileiro (2013), É membro do Conselho da Cinemateca Brasileira. autran@ufscar.br 


\section{Referências}

ALMEIDA, C. A. O cinema como agitador de almas: Argila, uma cena do Estado Novo. São Paulo: Annablume, 1999.

AMARAL, A. A. do. Carta a Getúlio Vargas. São Paulo: Arquivo Cinédia, 1931.

ATA da $2^{\text {a }}$ Sessão Preparatória para a $1^{\text {a }}$ Convenção de Produtores Nacionais. Rio de Janeiro: Arquivo Cinédia, 23 jan. 1932.

AUTRAN, A. O pensamento industrial cinematográfico brasileiro. São Paulo: Hucitec, 2013.

BERARDI, M. La vida imaginada - Vida cotidiana y cine argentino 1933-1970. Buenos Aires: Ediciones del Jilguero, 2006.

BERNARDET, J.-C. Cinema brasileiro: propostas para uma história. $2^{\circ}$ ed revista e ampliada. São Paulo: Companhia das Letras, 2009.

CAMPODÓNICO, R. H. Trincheras de celulóide. Bases para una historia político-económica del cine argentino. Madri: Havana / Fundación Autor: Universidad de Alcalá: FINCL, 2005.

CARIJÓ, A. de M. (Relator). Associação Cinematográfica de Produtores Brasileiros - Relatório da Diretoria - Biênio de 2-6-34 a 2-6-36. Rio de Janeiro: Associação Cinematográfica de Produtores Brasileiros, 1937.

FAUSTO, B.; DEVOTO, F. J. Brasil e Argentina - Um ensaio de história comparada (1850-2002). São Paulo: Editora 34, 2004.

GETINO, Octavio. Cine argentino - Entre lo posible y lo deseable. Buenos Aires: Ciccus, 1998.

GOMES, P. E. S. Humberto Mauro, Cataguases, Cinearte. São Paulo: Perspectiva / Ed. da Universidade de São Paulo, 1974.

GONÇALVES, M. R. "Romance proibido": a ficção cinematográfica a serviço da propaganda no Estado Novo. In: CONGRESSO BRASILEIRO DE CIÊNCIAS DA COMUNICAÇÃO, 32, 2009, Curitiba. Anais... Curitiba: Intercom - Sociedade Brasileira de Estudos Interdisciplinares da Comunicação, 2009. Disponível em: < http://www.intercom.org.br/papers/nacionais/2009/resumos/R4-2604-1. pdf>. Acesso em: 20 jul. 2017.

JOHNSON, R. The film industry in Brazil - Culture and the State. Pittsburgh: University of Pittsburgh Press, 1987.

KARUSH, M. B. Cultura de clase - Radio y cine en la creación de una Argentina dividida (19201946). Buenos Aires: Ariel, 2013.

KRIGER, C. Cine y peronismo - El Estado en escena. Buenos Aires: Siglo Veintiuno, 2009.

MARANGHELLO, C. Cine y Estado - Del proyecto conservador a la difusión peronista. In: ESPAÑA, Claudio (Org.). Cine argentino - Industria y clasicismo - 1933/1956. V. II. Buenos Aires: Fondo Nacional de las Artes, 2000. P. 22-159.

Breve historia del cine argentino. Barcelona: Laertes, 2005.

MARIÑO, C. N. G. Los usos de lo nacional en el desarollo de un proyecto cinematográfico en Argentina y Brasil en la primera etapa del sonoro. 2016. Tese (Doutorado em História). Universidade de Buenos Aires, Buenos Aires.

NÚBILA, D. di. La época de oro - Historia del cine argentino I. $2^{\circ}$ Ed. Buenos Aires: Ediciones del Jilguero, 1998. 
PELA. Indústria nacional de filmes cinematográficos. Diário Carioca, Rio de Janeiro, 12 fev. 1932. p. 3. PROPUGNANDO pelo desenvolvimento do cinema nacional. A Pátria, Rio de Janeiro, 3 mar. 1932. SIMIS, A. Estado e cinema no Brasil. São Paulo: Annablume / Fapesp, 1996.

SOUZA, J. I. de M. O Estado contra os meios de comunicação (1889-1945). São Paulo: Annablume / Fapesp, 2003.

VIANY, A. Introdução ao cinema brasileiro. Rio de Janeiro: Instituto Nacional do Livro, 1959.

Artigo recebido em 2 de outubro de 2017 e aprovado em 16 de abril de 2018. 